\title{
I. Preface
}

In the 1960s the monks at Haein Monastery in South Korea undertook the task of making twelve sets of xylographs from the blocks preserved in their buildings. One of these sets was acquired by Dr. Elizabeth Huff, then the Head Librarian of the East Asiatic Library of the University of California at Berkeley. When the more than 1400 volumes had finally all arrived at the Library, it was obvious that the collection would be difficult to use because there were few reference aids and those were mainly listings of titles in sequential order with no connection to the bound volumes. Recognizing the value of such material for scholars, a request was made to the Center for Japanese and Korean Studies at the University for funds to provide for research assistance in the task of cataloging it. Mr. Ronald Epstein, then a graduate student in the University, was the first of the assistants and undertook the examination of the volumes for information contained within them as well as checking the completeness of the set held by the Library. Later, Mr. Sung-bae Park joined the newly established Group in Buddhist Studies as a graduate student and became a research assistant on a second grant from the Center. By 1974 the catalogue had grown from its beginning as an aid to finding titles within the volumes to a more comprehensive description of each work. Mr. Park became a partner in the project and with a group of new assistants the expansion of the scope of the catalogue was under- 
viii

taken. Ms. Janet Gyatso, a graduate student in the Group in Buddhist Studies, Mr. Kenneth Eastman from the Oriental Languages Department, Ms. Sheila Regan, graduate student in the Group in Asian Studies, Mr. Kurt Schwalbe from the Graduate Theological Union, Mr. Brian Galloway and K. Douglass provided the necessary help for the final stage of compilation and the detailed and often tedious tasks of rechecking the previous work. A number of typists have transferred the information from work cards into manuscript form. Most notable among these have been Mr. Robin Yates and Ms. Katrina McCleod, graduate students in the Department of Oriental Languages. Their careful attention to the details of the content was an essential part of the preparation. Others who have helped at some stage in the project have been Mr. David Schneider, Ms. Mary Brown, Ms. Carolyn Yoshimura, Ms. Beth Upton, Mr. C.S. Kim, Mr. B.K. Woo, and Mr. Carl Bielefeldt.

Without the support of the Center for Japanese and Korean Studies, the work could hardly have been begun, much less have assumed the final form. The Directors, Professors Robert Bellah and Thomas Smith, have during their tenures been supportive and helpful at every step, and Ms. Julia Cleland, the Administrative Assistant, always a willing helper with the details of grants and student assistants. Throughout, Mr. Raymond Tang, now the Head Librarian of the East Asiatic Library, Mr. Charles Hamilton, Chief Cataloguer, and Mr. Y.K. Choo, the Korean Cataloguer, have given all possible assistance.

As the catalogue neared completion, the welcome news came that Dongguk University was publishing a complete set of the material in photo-reprint. Under the direction of President S.K. Lee, that University has made available in 47 volumes the facsimiles of the xylographs made directly from the blocks. In addition Prof. K.Y. Rhi and staff compiled a comprehensive catalogue in Korean, which is vol. 48 of the newly published set. It was a fitting project that a Buddhist University in Korea marked its 70th Anniversary with a new version of the canon.

LEWIS R. LANCASTER Department of Oriental Languages University of California, Berkeley 